\title{
Glenohumeral internal rotation deficit in throwing athletes: current perspectives
}

This article was published in the following Dove Press journal: Open Access Journal of Sports Medicine

\author{
Michael B Rose \\ Thomas Noonan \\ Steadman Hawkins Clinic, University \\ of Colorado School of Medicine, \\ Denver, CO, USA
}

\begin{abstract}
Glenohumeral internal rotation deficit (GIRD) is an adaptive process in which the throwing shoulder experiences a loss of internal rotation (IR). GIRD has most commonly been defined by a loss of $>20^{\circ}$ of IR compared to the contralateral shoulder. Total rotational motion of the shoulder is the sum of internal and external rotation and may be more important than the absolute value of IR loss. Pathologic GIRD has been defined as a loss of IR combined with a loss of total rotational motion. The leading pathologic process in GIRD is posterior capsular and rotator-cuff tightness, due to the repetitive cocking that occurs with the overhead throwing motion. GIRD has been associated with numerous pathologic conditions, including posterior superior labral tears, partial articular-sided rotator-cuff tears, and superior labral anterior-to-posterior tears. The mainstay of treatment for patients with GIRD is posterior capsular stretching and strengthening to improve scapular mechanics. In patients who fail nonoperative therapy, shoulder arthroscopy can be performed. Arthroscopic surgery in the high-level throwing athlete should be to restore them to their functional baseline with the minimum amount of intervention possible.
\end{abstract} Keywords: GIRD, throwing athlete, internal impingement, shoulder

\section{Introduction}

Glenohumeral $(\mathrm{GH})$ internal rotation deficit (GIRD) is an adaptive process in which the throwing shoulder experiences a loss of IR. Currently, GIRD can be defined by a loss of $>20^{\circ}$ of IR compared to the contralateral shoulder (Table 1). ${ }^{1-3}$ However, not all GIRD is pathologic, and decreased IR (compared to nonthrowing shoulder) can exist without concomitant shoulder pathology when total rotational motion (TRM) of the shoulders is symmetric. ${ }^{4}$ This is partly due to increased retrotorsion (decreased anteversion) of the humerus, which shifts the arc of motion more posteriorly (external). Pathologic GIRD, in contrast, exists when there is a loss of TRM $>5^{\circ}$ compared to the contralateral shoulder. This $5^{\circ}$ change has been associated with decreased shoulder strength $^{5}$ and increased injury rates in baseball players. ${ }^{6-8}$

First described over 50 years ago, the physical exam findings of increased external rotation (ER) and decreased IR have been well documented in the shoulders of throwing athletes. ${ }^{9-11}$ Bennett was the first to describe the pathologic finding in overhead athletes of a posteroinferior glenoid-bone spur termed the "Bennett lesion", ${ }^{12}$ now known to be due to traction of the inferior GH ligament (IGHL). In 1995, Davidson et al coined the term "internal impingement" to describe the intra-articular pathology found at the time of shoulder arthroscopy in overhead athletes. ${ }^{13}$ However, it was not until Burkhart et al's landmark three-part series on the disabled throwing shoulder that the pathologic process
Correspondence: Thomas Noonan Steadman Hawkins Clinic, University of Colorado School of Medicine, 8200 East Belleview Avenue - 615, Greenwood Village, Denver, CO 80III, USA

Tel +l 3036943333

Email tnoonan@shcdenver.com 
of GIRD was brought into mainstream orthopedics. ${ }^{2,14,15}$ This series elucidated many of the concepts currently used to guide the treatment of throwing athletes, including the kinetic chain of throwing and scapular dyskinesia.

The leading pathologic process in GIRD is posterior capsular and rotator-cuff tightness, due to the repetitive cocking that occurs with the overhead throwing motion. ${ }^{15,16}$ Achieving increased ER in the maximally abducted position is thought to help increase throwing velocity. ${ }^{17,18}$ During pitching, biomechanical studies have shown shoulder ER can exceed $160^{\circ}$, IR acceleration can exceed $6,000^{\circ} /$ second, and IR torque can exceed $60 \mathrm{~N} / \mathrm{m} .{ }^{19}$ These kinematic extremes place a high amount of stress on the static and dynamic stabilizers of the shoulder, including the rotator cuff, joint capsule, and labrum. With each pitch, these structures are loaded to levels that approach their ultimate load to failure, making them extremely vulnerable to injury. ${ }^{20}$ Although a single traumatic event can lead to a shoulder injury, more commonly it is repetitive overuse that leads to numerous pathologic conditions, including posterior labral tears, partial articular-sided posterosuperior rotator-cuff tears, and superior labral anterior-to-posterior (SLAP) tears. ${ }^{20,21}$ In addition to shoulder pathology, patients also display scapular dyskinesia ${ }^{15}$ and are predisposed to ulnar collateral ligament (UCL) tears at the elbow. ${ }^{22}$

The throwing motion is an extremely complex process in which remarkable velocities and extreme forces are repetitively generated (Figure 1). Mobility and stability are often directly at odds with each other, leading to the idea of the "thrower's paradox" coined by Wilk et al. ${ }^{23}$ While throwers may not complain of frank instability, they do have a component of pathologic laxity or microinstability that predisposes them to injury. ${ }^{24}$ Balancing this dichotomy allows athletes to achieve maximal performance while pitching. The goal of this review is to provide an update on the diagnosis, associated pathology, and treatment of GIRD in throwing athletes.

Table I Definitions for common terminology used in the diagnosis and treatment of GIRD

\begin{tabular}{|c|c|}
\hline Term & Definition \\
\hline $\begin{array}{l}\text { GIRD (glenohumeral internal rotation } \\
\text { deficit) }\end{array}$ & Loss of internal rotation (IR) of $\geq 20^{\circ}$ or greater compared to contralateral shoulder \\
\hline TRM (total rotational shoulder motion) & $\begin{array}{l}\text { Summation of internal and external rotation (ER) measured at } 90^{\circ} \text { of shoulder abduction; should not } \\
\text { exceed } 187^{\circ}\end{array}$ \\
\hline Internal impingement & $\begin{array}{l}\text { Contact between the greater tuberosity of the humerus and the posterior superior glenoid rim } \\
\text { leading to impingement of the posterosuperior labrum and articular side of the rotator cuff }\end{array}$ \\
\hline External impingement & $\begin{array}{l}\text { Contact between and greater tuberosity of the humerus and the acromion leading to impingement } \\
\text { on the bursal side of rotator cuff }\end{array}$ \\
\hline $\begin{array}{l}\text { SLAP (superior labrum, anterior to } \\
\text { posterior) }\end{array}$ & Tear of superior labrum from anterior to posterior \\
\hline ABER (abduction and ER) & $\begin{array}{l}\text { Position of the shoulder in the cocking phase of throwing where shoulder abduction is } \geq 90^{\circ} \text { and ER } \\
\text { can achieve up to } 160^{\circ}\end{array}$ \\
\hline IGHL (inferior glenohumeral ligament) & $\begin{array}{l}\text { Capsular thickening that provides restraint to translation of the humeral head; anterior band prevents } \\
\text { posterior translation in } A B E R \text { and posterior band prevents anterior translation }\end{array}$ \\
\hline $\begin{array}{l}\text { PASTA (partial articular-sided } \\
\text { supraspinatus tear) }\end{array}$ & $\begin{array}{l}\text { Articular-sided partial-thickness tear of the posterior supraspinatus tendon caused by internal } \\
\text { impingement of the greater tuberosity on the posterior labrum }\end{array}$ \\
\hline
\end{tabular}

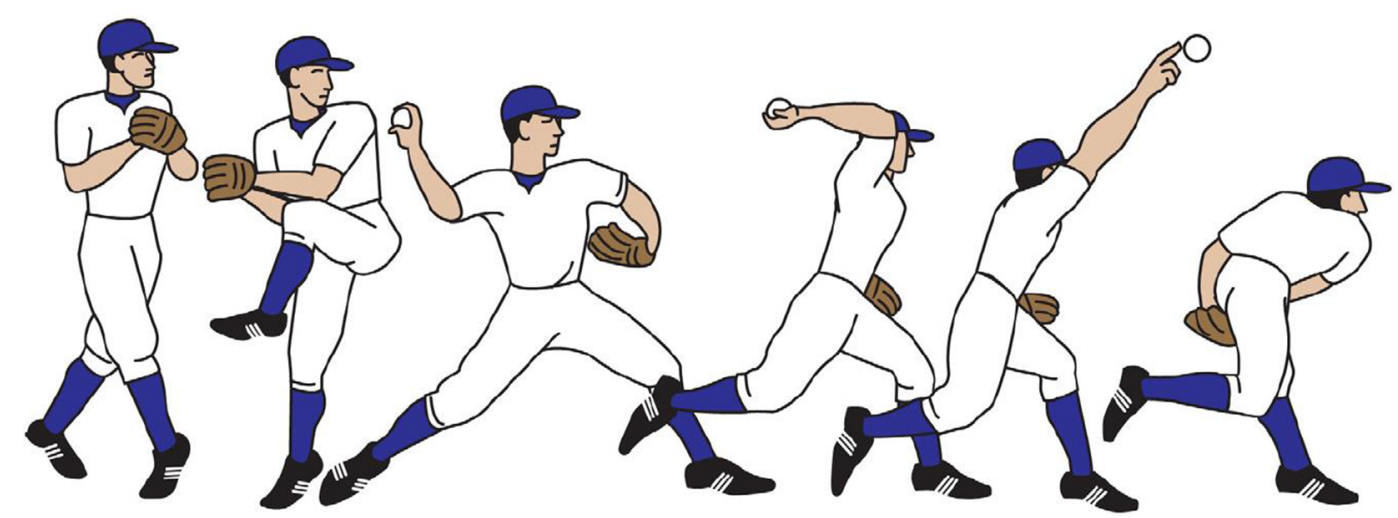

Figure I The six phases of the throwing motion: windup, early cocking, late cocking, acceleration, ball release and deceleration, and follow-through. Note: Reproduced with permission from Braun S, Kokmeyer D, Millett PJ. Shoulder injuries in the throwing athlete. J Bone Joint Surg Am. 2009;9I (4):966-978. Available from: https://journals.Iww.com/jbjsjournal/Abstract/2009/04000/Shoulder_Injuries_in the_Throwing_Athlete.29.aspx. ${ }^{20}$ 


\section{Diagnosis}

\section{History and physical exam}

In athletes with pathologic GIRD, shoulder stiffness, the need for a prolonged warm-up, and loss of velocity (dead arm) are often the initial complaints. ${ }^{25}$ Pain is often aspecific, localizing to the posterior shoulder, and the late cocking position is often provocative. ${ }^{26}$ Palpation of the posterior joint line and surrounding soft tissue can reproduce pain. ${ }^{27}$ Due to the high prevalence of GIRD in overhead throwers, a high index of suspicion is necessary for any throwing athlete who presents with shoulder symptoms. Therefore, all throwers with shoulder pain must be assessed for passive IR and TRM of the shoulder. The authors' preferred method to assess loss of IR of the shoulder is to have the patient lie supine on the examination table. The examiner can then bring both arms into $90^{\circ}$ of shoulder abduction and $90^{\circ}$ of elbow flexion. Maximum passive ER and IR are then assessed in the throwing shoulder compared to the contralateral extremity, and differences can be measured using a goniometer (Figure 2). Importantly, maximum passive IR is defined as the point just before the scapula begins to lift from the examining surface. ${ }^{28}$ Although the exact definition is debated, a difference of $20^{\circ}$ or more when compared to the contralateral side is generally considered diagnostic of GIRD. The sum of maximum ER and IR equals the TRM of the shoulder. In most overhead-throwing athletes, TRM

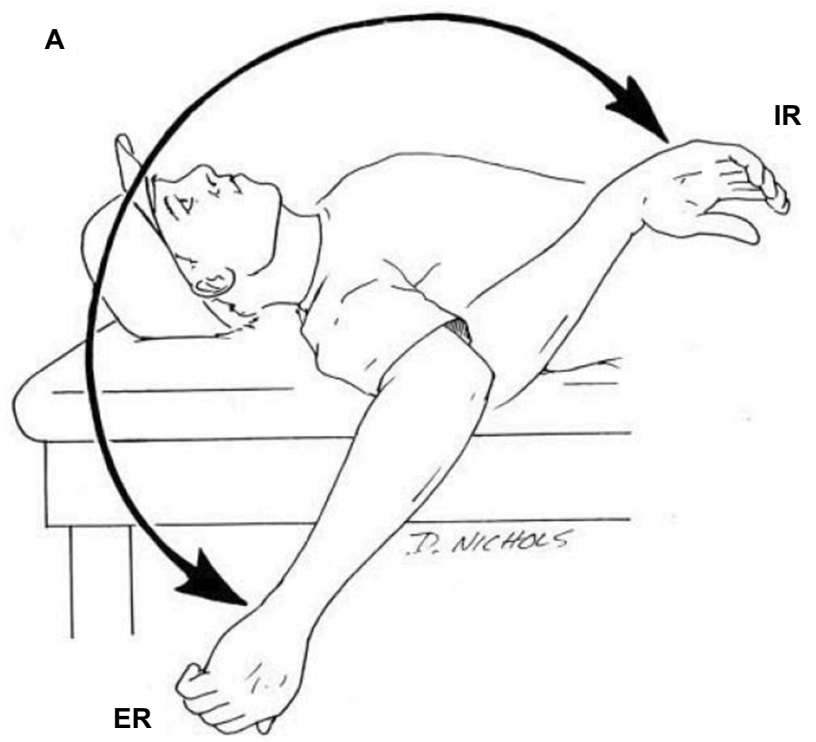

Figure 2 Total rotation motion of the shoulder is the summation of passive ER and IR.

Notes: In overhead throwers, the arc of motion is shifted more posteriorly (external), which can lead to GIRD. Copyright @20II. SAGE journals. Reproduced from Wilk KE, Macrina LC, Fleisig GS, et al. Correlation of glenohumeral internal rotation deficit and total rotational motion to shoulder injuries in professional baseball pitchers. Am J Sports Med. 20I I;39(2):329-335. ${ }^{8}$

Abbreviations: GIRD, glenohumeral internal rotation deficit; ER, external rotation ; $\mathrm{IR}$, internal rotation. should be symmetric bilaterally. This method is preferred to measuring IR by assessing the vertebral level that can be reached when rotating the arm up the back, because it has been shown to have greater reliability ${ }^{29}$ and is not affected by scapulothoracic or elbow motion. ${ }^{30}$

Posterior-shoulder tightness can be assessed as described by Tyler et al. ${ }^{31}$ This is performed by having the subject lie in the lateral decubitus position with the throwing shoulder up. With the shoulder in $90^{\circ}$ of abduction and neutral rotation (scapula stabilized), the arm is maximally adducted (lowered toward the floor). The distance that the medial epicondyle of the humerus travels in centimeters is recorded. Posteriorshoulder tightness is then calculated as the difference between the throwing and nonthrowing shoulders. Every $1 \mathrm{~cm}$ loss of adduction correlates with an $\sim 5^{\circ}$ loss of IR. Therefore, a 4 $\mathrm{cm}$ deficit would equate to a $20^{\circ}$ loss of IR and a diagnosis of GIRD. Myers et al confirmed this in a series of throwers, showing the average amount of posterior-shoulder tightness was $4.2 \mathrm{~cm}$ in subjects with internal impingement compared to $0.9 \mathrm{~cm}$ in subjects throwers without impingement. ${ }^{32} \mathrm{To}$ assess internal impingement in a throwing athlete with GIRD further, Meister et al developed a test termed "posterior impingement sign" to look for posterosuperior labral tears and partial articular-sided supraspinatus tear (PASTA) lesions. ${ }^{33}$ The shoulder is brought into maximum passive abduction and ER (late cocking). The presence of deep posterior-shoulder pain is considered positive.

In addition to posterior-shoulder tightness, approximately two-thirds of pitchers with GIRD display a sulcus sign on exam. ${ }^{10}$ This is thought to be due to laxity of the rotator interval structures (coracohumeral and superior GH ligament), due to repetitive cocking while throwing. ${ }^{34}$ Another classic pathologic finding in the examination of the throwing athlete includes so-called SICK scapula, ${ }^{15}$ which consists of scapular malposition, inferior medial border prominence, coracoid pain and malposition, and dyskinesis of scapular movement. Static position of the scapula is best assessed from behind, and it is often helpful to draw the bony prominences bilaterally for comparison. Active motion can then be assessed by having the patient perform maximum forward elevation, and any dyskinesia can be detected. Finally, all throwers with shoulder pain in our clinic are evaluated for active and passive motion in all planes (forward flexion, extension, abduction, cross-body adduction), manual muscle-strength testing of the rotator cuff, impingement findings (Hawkins-Neer testing), SL and bicep pathology (active compression and Speed's test), and instability (apprehension, load and shift, and jerk testing). Specifically, for throwers with painful shoulders, evaluation of 
the entire kinetic chain of throwing is performed by a team of trained physical therapists and includes assessments of core strength and hip mechanics.

\section{Imaging}

Radiography can be nondiagnostic in athletes with GIRD. We routinely obtain a standard shoulder series (AP, Grashey, axillary, and scapularY) in patients who present to our clinic with a new complaint of shoulder pain. Occasionally, a posterior glenoid osteophyte (Bennett's lesion) can be seen on axillary radiography and sclerosis of the posterior glenoid rim seen on computed tomography. ${ }^{35} \mathrm{MRI}$ is the modality of choice for the diagnosis of GIRD to rule out any concomitant pathology. The MRI features of posterior glenoid internal impingement have been described, and include supraspinatus and anterior infraspinatus partial undersurface tears, bony cystic changes at the posterosuperior humeral head, glenoid chondral wear, and labral pathology, including posterior SL tears and type II SLAP tears. ${ }^{36}$ Superoposterior subluxation of the humeral head and thickened appearance of the posterior band of the IGHL can also be seen (Figure 3A). ${ }^{37} \mathrm{MR}$ arthrography (MRA) of the shoulder offers increased sensitivity for the detection of articular-surface partial-thickness rotator-cuff tears and SLAP lesions over conventional MRI. ${ }^{38,39}$ Additionally, MRA performed in the abduction and external rotation (ABER) position allows the posterosuperior rotator cuff to relax, permitting better visualization of a rotator-cuff tear (Figure 3B). ${ }^{40}$ Placing the shoulder in ABER puts the biceps anchor on tension, allowing for visualization of otherwise nondisplaced SLAP tears. For these reasons, MRA in the ABER position should be considered in all symptomatic overhead athletes. $^{41}$

\section{Pathology}

Although GIRD in isolation is not a pathologic process, throwers with GIRD often present to the clinic due to the development of shoulder pathology. The pathologic process in throwing shoulders with GIRD can be divided into intra-articular shoulder pathology (labrum, joint capsule, articular-sided rotator cuff), extra-articular shoulder pathology (bursal-sided rotator cuff, acromion), and pathology of the throwing kinetic chain (lower extremity, core, scapula, and elbow). We discuss each in detail.

\section{Posterior-shoulder tightness and humeral retrotorsion}

Traditionally, the major pathologic process in GIRD was thought to be contracture of the posterior GH-joint capsule and the posterior band of the IGHL. ${ }^{2,16,42-45}$ In high-level throwers, the posterior capsule was found to be thicker in the dominant shoulder compared to the contralateral extremity. ${ }^{46}$ Experimentally, posterior capsular plication has replicated the biomechanical changes that occur in the throwing shoulder. ${ }^{47}$ Following simulated posteroinferior capsular tightness (with resultant GIRD), GH contact pressure and rotator-cuff impingement significantly increases. Additionally, with as little as 5\% GIRD, translational changes in the humeral head occur, including increased superior displacement of the humeral head in maximum abduction and ER (ABER). ${ }^{16,43}$ These shifts in humeral head center of rotation have implications for injury, due to altered joint kinematics. ${ }^{3}$ Interestingly, more recent data have shown that posterior rotator-cuff tightness, not just capsular contracture, may contribute to GIRD. ${ }^{48}$ This idea is also supported by studies showing GIRD can change as much as $15 \%$ after a single
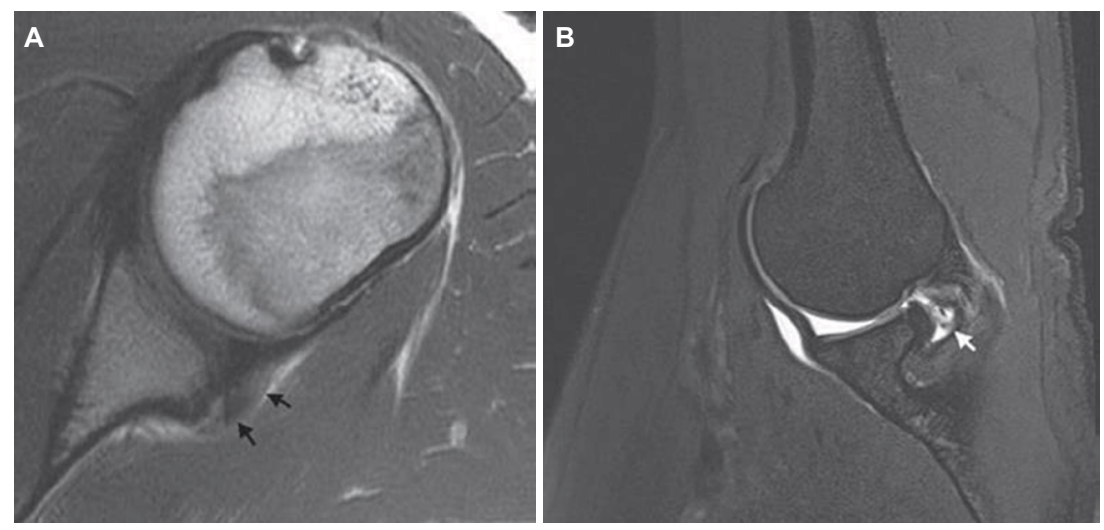

Figure 3 Magnetic resonance imaging of the throwing shoulder.

Notes: $(\mathbf{A})$ Axial MRI of the shoulder $\left(T_{1}\right)$, with small black arrows showing thickening of the posterior capsule; $(\mathbf{B})$ MR arthrography $\left(T_{2}\right)$ performed in the ABER position, with small white arrow showing an articular-sided tear in the supraspinatus tendon. Copyright @20I5. John Wiley and Sons. Reproduced with permission from Fessa CK, Peduto A, Linklater J, Tirman P. Posterosuperior glenoid internal impingement of the shoulder in the overhead athlete: pathogenesis, clinical features and MR imaging findings. J Med Imaging Radiat Oncol. 2015;59(2): 182-187.36

Abbreviations: $A B E R$, abduction and external rotation. 
throwing exposure, ${ }^{49,50}$ making the loss of IR too rapid for capsular contracture alone. Therefore, the terminology of posterior-shoulder tightness to include all soft tissue (capsule and cuff) has been proposed as a better descriptor of the pathology that occurs. ${ }^{31}$

Although the adaptive changes seen in GIRD were historically thought to affect only soft tissue, studies have shown bony changes, including increased humeral retrotorsion (decreased anteversion) in collegiate ${ }^{51}$ and professional baseball pitchers. ${ }^{52} \mathrm{~A}$ recent study showed professional baseball pitchers displayed significantly greater humeral retrotorsion in their dominant arm compared with those without GIRD. Pitchers also displayed a greater side-to-side difference in humeral torsion. ${ }^{52}$ In youth and high school pitchers, agerelated increases in GIRD were correlated with increased humeral retrotorsion, not soft-tissue changes. ${ }^{53}$ Bony changes to the scapula also occur in the dominant arm, with significantly increased glenoid retroversion seen in baseball players compared to controls. ${ }^{54}$ Interestingly, many authors believe increased bony adaptation is protective to the soft-tissue stabilizers of the shoulder, ${ }^{32,51,55}$ the idea being increased ER gain through bony changes protects the shoulder from excess stress on the anterior capsuloligamentous structures. ${ }^{56}$

\section{Rotator-cuff pathology}

Tears of the rotator cuff are common in the throwing athlete, and MRI of the dominant shoulder in asymptomatic throwers shows cuff tears in up to $40 \% .{ }^{57}$ In this population, failure of the rotator cuff is multifactorial, caused by supraphysiological strain, defects in the kinetic chain (notably the scapula), and anterior insability. ${ }^{58}$ Rotator-cuff pathology in patients with GIRD can be separated into two categories: acute traumatic tears due to overload during deceleration (minority of tears), and partial- or full-thickness degenerative tears due to impingement (internal > external). The degenerative fraying on the articular side of the rotator cuff that is seen in throwers was first described in the first half of the twentieth century ${ }^{12}$ and better defined at the time of arthroscopy by Andrews et $\mathrm{al}^{59}$ and Walch et al. ${ }^{35}$ The etiology of articular-sided tears is thought to be caused by a tight posterior capsule, leading to internal impingement, repetitive microtrauma, and shear stress on under-surface fibers, which have limited intrinsic repair potential. ${ }^{58}$ Importantly, the shoulder capsule maintains a broad insertion on greater tuberosity; therefore, by definition any articular-sided partial-thickness rotator-cuff tears must involve compromise of the superior capsule ${ }^{60}$ and subsequently permit increased GH translation and shoulder laxity. ${ }^{61}$
Although much of the focus on GIRD centers around the cocking phase of throwing (Figure 1), biomechanical studies have shown that enormous forces are placed upon the shoulder stabilizers during ball release. During arm deceleration, posterior sheer force can reach $400 \mathrm{~N}$ and compression of the humeral head against the glenoid can exceed 1,000 N. ${ }^{19}$ For this reason, the instant just before ball release has been defined as a critical phase of throwing. After ball release, extreme force and torque is placed upon the rotator cuff as the arm decelerates, which can result in tensile failure and an acute traumatic rupture. ${ }^{19}$

\section{Labral pathology}

The hallmark lesion of GIRD and internal impingement is a posterosuperior labral tear. ${ }^{35,62}$ Impingement of the greater tuberosity against the glenoid rim during late cocking causes lesions to the posterosuperior labrum and articular side of the supraspinatus tendon. Although this can be a normal physiological occurrence in maximum ABER, the biomechanics of repetitive throwing intensify this contact. ${ }^{32}$ In addition to posterior labral tears, subjects with GIRD develop SLAP tears. Andrews et $\mathrm{al}^{63}$ and Snyder et $\mathrm{al}^{64}$ pioneered our understanding of these tears in throwing athletes. Although the function of the superior labrum is still debated, most agree it is important for concavity compression of the shoulder as well as an attachment site for soft-tissue stabilizers. ${ }^{1}$ The mechanism of SLAP tears in overhead athletes is thought to be multifactorial, but most authors agree the "peel back" that occurs during ABER ${ }^{65}$ contributes to SLAP pathology. During the throwing motion, superior migration of the humeral head can increase the stress on the superior labrum and bicep anchor. Kinematic studies have shown that during the cocking phase of throwing, superior shear forces can exceed 250 N. ${ }^{19}$ Additionally, bicep contraction in a lengthened position places tensile stress on the bicep anchor, which may lead to SL tears. ${ }^{19}$ Some authors argue that SLAP lesions are adaptive and allow for supraphysiological ER, as the biceps anchor is a stabilizer in the late-cocking position.

\section{Kinetic chain}

As described by Burkhart et al in the kinetic chain of throwing, the legs and trunk generate force, the shoulder regulates and funnels force, and the arm delivers force to the ball. ${ }^{15}$ Approximately half of the kinetic energy generated during throwing is transferred to the arm through the scapulothoracic joint, making the scapula crucial in the kinetic chain for throwing. ${ }^{15}$ A SICK scapula can lead to altered kinematics in the $\mathrm{GH}$ and acromioclavicular joints, leading to anterior-shoulder 
pain, coracoid tenderness, acromioclavicular-joint pain with overhead activities, and decreased range of motion, specifically forward flexion. ${ }^{15}$ Another aspect of the kinetic chain that can be injured in overhead throwing with GIRD is the elbow. Many studies have shown a correlation between GIRD and injuries to the elbow UCL in throwers. ${ }^{22,55,66}$ Increasing the amount of ER increases the valgus load seen at the elbow in the cocking phase. However, a recent study showed there was no significant difference in mean dominant-arm humeral retrotorsion between pitchers with previous UCL reconstructions compared to uninjured controls. ${ }^{67}$ Therefore, it may be decreased TRM, and not just GIRD, that predisposes pitchers to UCL injuries.

\section{Treatment and outcomes Nonsurgical}

The mainstay of treatment for patients with GIRD is posterior capsular stretching and strengthening to improve scapular mechanics. ${ }^{68}$ In our clinical experience, the success rates for a prolonged course of physical therapy cannot be overstated when discussing the treatment of throwing athletes with painful shoulders. Active stretching in throwing athletes has generally been performed via the sleeper stretch and the cross-body stretch. These stretches were first described by Burkhart et al in part 1 of their series on the disabled throwing shoulder. ${ }^{2}$ The sleeper stretch is performed with subjects lying on their side with their shoulder and elbow flexed to $90^{\circ}$ and the scapula stabilized. The contralateral extremity is then used to rotate internally the throwing shoulder maximally. The cross-body stretch is performed with the patient standing and the shoulder flexed to $90^{\circ}$. The contralateral extremity is then used maximally to adduct the throwing shoulder horizontally by applying pressure to the elbow. Several authors have prospectively studied additional stretching methods, including prone-passive stretching, ${ }^{69}$ all-fours posterior stretching, ${ }^{70}$ and the muscle-energy technique. ${ }^{71}$

Multiple studies have shown the benefit of stretching in symptomatic GIRD patients. ${ }^{72,73}$ In addition to improving IR deficits and TRM, stretching has also been shown to increase acromiohumeral distance in throwing with GIRD. ${ }^{74}$ In asymptomatic professional baseball pitchers, 2 minutes of stretching after a short pitching session has been shown to restore motion back to prepitching levels. ${ }^{75}$ Mine et al recently published a systematic review on the effectiveness of stretching (cross-body and sleeper) in asymptomatic patients with GIRD. ${ }^{76}$ In this study, they analyzed 553 subjects in ten randomized controlled trails in the English- and Japaneselanguage literatures. They concluded that there was moderate evidence to support the short-term effects of stretching in patients with asymptomatic GIRD. In addition to stretching alone, research has shown that instrumented manual therapy along with a stretching program improves shoulder motion in baseball players. ${ }^{77}$ Newer nonoperative modalities like the muscle-energy technique and myofascial release ${ }^{78}$ also play a role in the treatment of GIRD, although more research is needed to study their effectiveness. In our clinic, athletes are seen by a physical therapist specialized in treating throwing athletes and immediately begun on a stretching program. Wilk et al outlined the phases of rehabilitation in the throwing athlete, which can progress from stretching to strengthening and eventually return to play. ${ }^{23}$

\section{Surgical}

In general, return-to-play rates after arthroscopic shoulder surgery in throwers are only fair, ${ }^{79-81}$ and surgery is recommended only for throwers that have exhausted nonsurgical treatment. Certain authors would argue that the goal of arthroscopic surgery in the high-level throwing athlete should be to restore them to their functional baseline with the minimum amount of intervention possible. Much controversy exists in the treatment of SLAP tears in throwers, and outcomes reported in the literature including return-to-play rates are quite variable. ${ }^{82-85}$ Many of the studies looking at surgical treatment of SLAP lesions included additional pathology, including rotator-cuff tears, making comparison difficult. For repair of type II SLAP tears specifically, a recent systematic review showed only $63 \%$ of overhead athletes returned to their previous level of play. Interestingly, athletes who underwent anchor repair had a slightly higher return-to-play rate compared with tack repair. ${ }^{86}$ Brockmeyer et al published a treatment algorithm for surgical treatment of SLAP tears, with a recommendation of repair of type II lesions in young, active patients. ${ }^{87}$ Surgical techniques for the treatment of SLAP lesions are also highly variable. A recent systematic review (26 papers, 1,162 patients) showed high heterogeneity in surgical technique, the largest percentage of studies reporting one to two absorbable suture anchors placed at the 11:00 and 1:00 positions. ${ }^{88}$ As opposed to fixing SLAP tears in throwing athletes, some authors have recently advocated for biceps tenodesis. ${ }^{79,89}$

Like SLAP repair, the treatment of articular-sided rotatorcuff tears in athletes is controversial. Cadaveric transtendinous repair of partial rotator-cuff tears has been shown to improve GH and subacromial contact pressure at the cost of a loss of ER. ${ }^{61}$ However, clinically, the results after rotatorcuff surgery for elite throwers are poor, and return-to-play 
rates are low. ${ }^{81,90-94}$ In throwers with severe GIRD and loss of TRM who have failed extensive nonoperative treatment, arthroscopic posteroinferior capsular release can be performed. In college-age throwing athletes, capsular release has been shown to improve patient reported outcome scores and GIRD significantly. ${ }^{95}$ Capsular release should be performed from 6:00 to 11:00 (right shoulder) to expose completely the muscle bellies of the posterior rotator cuff. ${ }^{96}$

\section{Discussion}

Due to the prevalence of single-sport specialization and increases in the throwing demand of overhead athletes, the prevalence of GIRD is increasing. Little leaguers have been shown to develop GIRD before even a passive increase in ER is seen on exam. ${ }^{97}$ Repetitive throwing leads to adaptive bony, capsuloligamentous, and muscular changes. Over time, these adaptive changes lead to pathologic kinematics and GIRD. Although these findings are commonly described in baseball pitchers, similar injuries may be observed in softball, tennis, handball, football, and even javelin throwers. ${ }^{98}$ Therefore, any overhead athlete that presents to the clinic with shoulder pain should be examined for GIRD. The diagnosis of GIRD is made clinically based upon decreased passive IR compared to the contralateral shoulder, and it is important to recognize that not all GIRD is pathologic. As the prevalence of GIRD increases, more research is needed on diagnosis and management of throwers with GIRD. Screening programs may be necessary, and prevention programs like those that have been adopted to prevent anterior cruciate ligament injuries in adolescent female athletes may be beneficial. However, currently data are lacking on the outcomes of preventive measures for asymptomatic throwers with GIRD. Additionally, limited level 1 data exist on which stretching methods are superior in patients with GIRD. As new nonoperative modalities become available, research will need to be done to study their effectiveness.

The mainstay of nonoperative treatment for patients with GIRD remains posterior capsular stretching. A comprehensive therapy protocol should also focus on the entire kinetic chain, including the lower extremity, core, and scapula. In symptomatic throwers who fail extensive nonoperative therapy, shoulder arthroscopy can be performed. It is important to recognize not all patients with GIRD carry the diagnosis of internal impingement, and these terms are not synonymous. However, pathologic GIRD may lead to numerous conditions, including posterosuperior labral tears, PASTA lesions, SLAP tears, and microinstability from rotator-interval laxity. In athletes with GIRD who do go on to develop pathology requiring surgical intervention, more research needs to be done on the optimal sur- gical management. For example, surgical treatment for SLAP tears and PASTA tears continues to remain highly controversial. A recent study showed bicep tenodesis may not have as good an outcome in pitchers as previously believed..$^{99}$ Therefore, the goal of arthroscopic surgery in the high-level throwing athlete should be to restore them to their functional baseline with the minimum amount of intervention possible. This may not mean restoring their shoulder to "normal", as they have adaptive changes that allow them to perform at such a high level.

\section{Disclosure}

The authors report no conflicts of interest in this work.

\section{References}

1. Kibler WB, Kuhn JE, Wilk K, et al. The disabled throwing shoulder: spectrum of pathology - 10-year update. Arthroscopy. 2013;29(1):141161.e126.

2. Burkhart SS, Morgan CD, Kibler WB. The disabled throwing shoulder: spectrum of pathology - part I: pathoanatomy and biomechanics. Arthroscopy. 2003;19(4):404-420.

3. Kibler WB, Sciascia A, Thomas SJ. Glenohumeral internal rotation deficit: pathogenesis and response to acute throwing. Sports Med Arthrosc Rev. 2012;20(1):34-38.

4. Manske R, Wilk KE, Davies G, Ellenbecker T, Reinold M. Glenohumeral motion deficits: friend or foe? Int J Sports Phys Ther. 2013;8(5): 537-553.

5. Amin NH, Ryan J, Fening SD, Soloff L, Schickendantz MS, Jones M. The relationship between glenohumeral internal rotational deficits, total range of motion, and shoulder strength in professional baseball pitchers. J Am Acad Orthop Surg. 2015;23(12):789-796.

6. Shanley E, Rauh MJ, Michener LA, Ellenbecker TS, Garrison JC, Thigpen CA. Shoulder range of motion measures as risk factors for shoulder and elbow injuries in high school softball and baseball players. Am J Sports Med. 2011;39(9):1997-2006.

7. Wilk KE, Macrina LC, Fleisig GS, et al. Deficits in glenohumeral passive range of motion increase risk of shoulder injury in professional baseball pitchers: a prospective study. Am J Sports Med. 2015;43(10):2379-2385.

8. Wilk KE, Macrina LC, Fleisig GS, et al. Correlation of glenohumeral internal rotation deficit and total rotational motion to shoulder injuries in professional baseball pitchers. Am J Sports Med. 2011;39(2):329-335.

9. King JW, Brelsford HJ, Tullos HS. Analysis of the pitching arm of the professional baseball pitcher. Clin Orthop Relat Res. 1969;67:116-123.

10. Bigliani LU, Codd TP, Connor PM, Levine WN, Littlefield MA, Hershon SJ. Shoulder motion and laxity in the professional baseball player. $\mathrm{Am}$ J Sports Med. 1997;25(5):609-613.

11. Brown LP, Niehues SL, Harrah A, Yavorsky P, Hirshman HP. Upper extremity range of motion and isokinetic strength of the internal and external shoulder rotators in major league baseball players. Am J Sports Med. 1988;16(6):577-585.

12. Bennett GE. Shoulder and elbow lesions distinctive of baseball players - 1947. Clin Orthop Relat Res. 2012;470(6):1531-1533.

13. Davidson PA, Elattrache NS, Jobe CM, Jobe FW. Rotator cuff and posterior-superior glenoid labrum injury associated with increased glenohumeral motion: a new site of impingement. J Shoulder Elbow Surg. 1995;4(5):384-390.

14. Burkhart SS, Morgan CD, Kibler WB. The disabled throwing shoulder: spectrum of pathology - part II: evaluation and treatment of SLAP lesions in throwers. Arthroscopy. 2003;19(5):531-539.

15. Burkhart SS, Morgan CD, Kibler WB. The disabled throwing shoulder: spectrum of pathology - part III: the SICK scapula, scapular dyskinesis, the kinetic chain, and rehabilitation. Arthroscopy. 2003;19(6):641-661. 
16. Gates JJ, Gupta A, McGarry MH, Tibone JE, Lee TQ. The effect of glenohumeral internal rotation deficit due to posterior capsular contracture on passive glenohumeral joint motion. Am J Sports Med. 2012;40(12):2794-2800.

17. Wang YT, Ford HT 3rd, Ford HT Jr, Shin DM. Three-dimensional kinematic analysis of baseball pitching in acceleration phase. Percept Mot Skills. 1995;80(1):43-48.

18. Stodden DF, Fleisig GS, McLean SP, Andrews JR. Relationship of biomechanical factors to baseball pitching velocity: within pitcher variation. J Appl Biomech. 2005;21(1):44-56.

19. Fleisig GS, Andrews JR, Dillman CJ, Escamilla RF. Kinetics of baseball pitching with implications about injury mechanisms. Am J Sports Med. 1995;23(2):233-239.

20. Braun S, Kokmeyer D, Millett PJ. Shoulder injuries in the throwing athlete. J Bone Joint Surg Am. 2009;91(4):966-978.

21. Gaber S, Zdravkovic V, Jost B. [The throwing shoulder]. Orthopade. 2014;43(3):223-229.

22. Lee BJ, Garrison JC, Conway JE, Pollard K, Aryal S. The relationship between humeral retrotorsion and shoulder range of motion in baseball players with an ulnar collateral ligament tear. Orthop J Sports Med. 2016;4(10):2325967116667497.

23. Wilk KE, Meister K, Andrews JR. Current concepts in the rehabilitation of the overhead throwing athlete. Am J Sports Med. 2002;30(1):136-151.

24. Ryu RK, Dunbar WH, Kuhn JE, McFarland EG, Chronopoulos E, Kim TK. Comprehensive evaluation and treatment of the shoulder in the throwing athlete. Arthroscopy. 2002;18(9 Suppl 2):70-89.

25. Corpus KT, Camp CL, Dines DM, Altchek DW, Dines JS. Evaluation and treatment of internal impingement of the shoulder in overhead athletes. World J Orthop. 2016;7(12):776-784.

26. Spiegl UJ, Warth RJ, Millett PJ. Symptomatic internal impingement of the shoulder in overhead athletes. Sports Med Arthrosc Rev. 2014;22(2):120-129.

27. Winter SB, Hawkins RJ. Comprehensive history and physical examination of the throwing shoulder. Sports Med Arthrosc Rev. 2014;22(2): 94-100.

28. Kibler WB, Chandler TJ, Livingston BP, Roetert EP. Shoulder range of motion in elite tennis players: effect of age and years of tournament play. Am J Sports Med. 1996;24(3):279-285.

29. Edwards TB, Bostick RD, Greene CC, Baratta RV, Drez D. Interobserver and intraobserver reliability of the measurement of shoulder internal rotation by vertebral level. J Shoulder Elbow Surg. 2002;11(1):40-42.

30. Lindenfeld TN, Fleckenstein CM, Levy MS, Grood ES, Frush TJ, Parameswaran AD. Reliability of a new clinical instrument for measuring internal and external glenohumeral rotation. Sports Health. 2015;7(4):312-317.

31. Tyler TF, Roy T, Nicholas SJ, Gleim GW. Reliability and validity of a new method of measuring posterior shoulder tightness. JOrthop Sports Phys Ther. 1999;29(5):262-264.

32. Myers JB, Laudner KG, Pasquale MR, Bradley JP, Lephart SM. Glenohumeral range of motion deficits and posterior shoulder tightness in throwers with pathologic internal impingement. Am J Sports Med. 2006;34(3):385-391.

33. Meister K. Injuries to the shoulder in the throwing athlete - part one: biomechanics/pathophysiology/classification of injury. Am J Sports Med. 2000;28(2):265-275.

34. Kuhn JE, Bey MJ, Huston LJ, Blasier RB, Soslowsky LJ. Ligamentous restraints to external rotation of the humerus in the late-cocking phase of throwing: a cadaveric biomechanical investigation. Am J Sports Med. 2000;28(2):200-205.

35. Walch G, Boileau P, Noel E, Donell ST. Impingement of the deep surface of the supraspinatus tendon on the posterosuperior glenoid rim: an arthroscopic study. J Shoulder Elbow Surg. 1992;1(5):238-245.

36. Fessa CK, Peduto A, Linklater J, Tirman P. Posterosuperior glenoid internal impingement of the shoulder in the overhead athlete: pathogenesis, clinical features and MR imaging findings. $J$ Med Imaging Radiat Oncol. 2015;59(2):182-187.
37. Tehranzadeh AD, Fronek J, Resnick D. Posterior capsular fibrosis in professional baseball pitchers: case series of MR arthrographic findings in six patients with glenohumeral internal rotational deficit. Clin Imaging. 2007;31(5):343-348.

38. Smith TO, Drew BT, Toms AP. A meta-analysis of the diagnostic test accuracy of MRA and MRI for the detection of glenoid labral injury. Arch Orthop Trauma Surg. 2012;132(7):905-919.

39. Magee T. 3-T MRI of the shoulder: is MR arthrography necessary? AJR Am J Roentgenol. 2009;192(1):86-92.

40. Tirman PF, Bost FW, Steinbach LS, et al. MR arthrographic depiction of tears of the rotator cuff: benefit of abduction and external rotation of the arm. Radiology. 1994;192(3):851-856.

41. Iyengar JJ, Burnett KR, Nottage WM, Harwin SF. The abduction external rotation (ABER) view for MRI of the shoulder. Orthopedics. 2010;33(8):562-565.

42. Bach HG, Goldberg BA. Posterior capsular contracture of the shoulder. J Am Acad Orthop Surg. 2006;14(5):265-277.

43. Fitzpatrick MJ, Tibone JE, Grossman M, McGarry MH, Lee TQ. Development of cadaveric models of a thrower's shoulder. $J$ Shoulder Elbow Surg. 2005;14(1 Suppl S):49S-57S.

44. Gerber C, Werner CM, Macy JC, Jacob HA, Nyffeler RW. Effect of selective capsulorrhaphy on the passive range of motion of the glenohumeral joint. J Bone Joint Surg Am. 2003;85-a(1):48-55.

45. Grossman MG, Tibone JE, McGarry MH, Schneider DJ, Veneziani S, Lee TQ. A cadaveric model of the throwing shoulder: a possible etiology of superior labrum anterior-to-posterior lesions. J Bone Joint Surg Am. 2005;87(4):824-831.

46. Takenaga T, Sugimoto K, Goto H, et al. Posterior shoulder capsules are thicker and stiffer in the throwing shoulders of healthy college baseball players: a quantitative assessment using shear-wave ultrasound elastography. Am J Sports Med. 2015;43(12):2935-2942.

47. Mihata T, Gates J, McGarry MH, Neo M, Lee TQ. Effect of posterior shoulder tightness on internal impingement in a cadaveric model of throwing. Knee Surg Sports Traumatol Arthrosc. 2015;23(2):548-554.

48. Bailey LB, Shanley E, Hawkins R, et al. Mechanisms of shoulder range of motion deficits in asymptomatic baseball players. Am J Sports Med. 2015;43(11):2783-2793.

49. Kibler WB, Sciascia A, Moore S. An acute throwing episode decreases shoulder internal rotation. Clin Orthop Relat Res. 2012;470(6): $1545-1551$.

50. Reinold MM, Wilk KE, Macrina LC, et al. Changes in shoulder and elbow passive range of motion after pitching in professional baseball players. Am J Sports Med. 2008;36(3):523-527.

51. Osbahr DC, Cannon DL, Speer KP. Retroversion of the humerus in the throwing shoulder of college baseball pitchers. Am J Sports Med. 2002;30(3):347-353.

52. Noonan TJ, Shanley E, Bailey LB, et al. Professional pitchers with glenohumeral internal rotation deficit (GIRD) display greater humeral retrotorsion than pitchers without GIRD. Am J Sports Med. 2015;43(6):1448-1454.

53. Hibberd EE, Oyama S, Myers JB. Increase in humeral retrotorsion accounts for age-related increase in glenohumeral internal rotation deficit in youth and adolescent baseball players. Am J Sports Med. 2014;42(4):851-858.

54. Drakos MC, Barker JU, Osbahr DC, et al. Effective glenoid version in professional baseball players. Am J Orthop (Belle Mead NJ). 2010;39(7): 340-344.

55. Dines JS, Frank JB, Akerman M, Yocum LA. Glenohumeral internal rotation deficits in baseball players with ulnar collateral ligament insufficiency. Am J Sports Med. 2009;37(3):566-570.

56. Crockett HC, Gross LB, Wilk KE, et al. Osseous adaptation and range of motion at the glenohumeral joint in professional baseball pitchers. Am J Sports Med. 2002;30(1):20-26.

57. Connor PM, Banks DM, Tyson AB, Coumas JS, D'Alessandro DF. Magnetic resonance imaging of the asymptomatic shoulder of overhead athletes: a 5-year follow-up study. Am J Sports Med. 2003;31(5):724-727. 
58. Shaffer B, Huttman D. Rotator cuff tears in the throwing athlete. Sports Med Arthrosc Rev. 2014;22(2):101-109.

59. Andrews JR, Broussard TS, Carson WG. Arthroscopy of the shoulder in the management of partial tears of the rotator cuff: a preliminary report. Arthroscopy. 1985;1(2):117-122.

60. Nimura A, Kato A, Yamaguchi K, et al. The superior capsule of the shoulder joint complements the insertion of the rotator cuff. $J$ Shoulder Elbow Surg. 2012;21(7):867-872.

61. Mihata T, McGarry MH, Ishihara Y, et al. Biomechanical analysis of articular-sided partial-thickness rotator cuff tear and repair. Am J Sports Med. 2015;43(2):439-446.

62. Jobe CM. Posterior superior glenoid impingement: expanded spectrum. Arthroscopy. 1995;11(5):530-536.

63. Andrews JR, Carson WG Jr, McLeod WD. Glenoid labrum tears related to the long head of the biceps. Am J Sports Med. 1985;13(5):337-341.

64. Snyder SJ, Karzel RP, Del Pizzo W, Ferkel RD, Friedman MJ. SLAP lesions of the shoulder. Arthroscopy. 1990;6(4):274-279.

65. Burkhart SS, Morgan CD. The peel-back mechanism: its role in producing and extending posterior type II SLAP lesions and its effect on SLAP repair rehabilitation. Arthroscopy. 1998;14(6):637-640.

66. Garrison JC, Cole MA, Conway JE, Macko MJ, Thigpen C, Shanley E. Shoulder range of motion deficits in baseball players with an ulnar collateral ligament tear. Am J Sports Med. 2012;40(11):2597-2603.

67. Meyer CJ, Garrison JC, Conway JE. Baseball players with an ulnar collateral ligament tear display increased nondominant arm humeral torsion compared with healthy baseball players. Am J Sports Med. 2017; 45(1):144-149.

68. Wilk KE, Macrina LC. Nonoperative and postoperative rehabilitation for injuries of the throwing shoulder. Sports Med Arthrosc Rev. 2014;22(2):137-150.

69. Hammons D, McChesney JW, Curtin M, Pfeiffer R, Thiede K. A randomized and blinded study for the treatment of glenohumeral internal rotation range of motion restriction: the prone-passive stretching technique. J Sports Med Allied Health Sci. 2015;1(2):1-9.

70. Murata K YH, Gamada K. Short-term effects of the all-fours posterior stretching technique for posterior shoulder tightness in high school baseball players: a single-blinded cluster randomized controlled trial. Jpn Soc Clin Sports Med. 2012;20(1):145-152.

71. Moore SD, Laudner KG, McLoda TA, Shaffer MA. The immediate effects of muscle energy technique on posterior shoulder tightness: a randomized controlled trial. J Orthop Sports Phys Ther. 2011;41(6): 400-407.

72. Cools AM, Johansson FR, Cagnie B, Cambier DC, Witvrouw EE. Stretching the posterior shoulder structures in subjects with internal rotation deficit: comparison of two stretching techniques. Shoulder Elbow. 2012;4(1):56-63.

73. Tyler TF, Nicholas SJ, Lee SJ, Mullaney M, McHugh MP. Correction of posterior shoulder tightness is associated with symptom resolution in patients with internal impingement. Am J Sports Med. 2010;38(1): 114-119.

74. Maenhout A, van Eessel V, van Dyck L, Vanraes A, Cools A. Quantifying acromiohumeral distance in overhead athletes with glenohumeral internal rotation loss and the influence of a stretching program. $A m J$ Sports Med. 2012;40(9):2105-2112.

75. Escamilla RF, Yamashiro K, Mikla T, Collins J, Lieppman K, Andrews JR. Effects of a short-duration stretching drill after pitching on elbow and shoulder range of motion in professional baseball pitchers. Am J Sports Med. 2017;45(3):692-700.

76. Mine K, Nakayama T, Milanese S, Grimmer K. Effectiveness of stretching on posterior shoulder tightness and glenohumeral internal rotation deficit: a systematic review of randomised controlled trials. $J$ Sport Rehabil. 2017;(4):294-305.

77. Bailey LB, Thigpen CA, Hawkins RJ, Beattie PF, Shanley E. Effectiveness of manual therapy and stretching for baseball players with shoulder range of motion deficits. Sports Health. 2017;9(3):230-237.
78. Le Gal J, Begon M, Gillet B, Rogowski I. Effects of self-myofascial release on shoulder function and perception in adolescent tennis players. J Sport Rehabil. Epub 2017 Sep 17.

79. Thorsness R, Alland JA, McCulloch CB, Romeo A. Return to play after shoulder surgery in throwers. Clin Sports Med. 2016;35(4):563-575.

80. Harris JD, Frank JM, Jordan MA, et al. Return to sport following shoulder surgery in the elite pitcher: a systematic review. Sports Health. 2013;5(4):367-376.

81. van Kleunen JP, Tucker SA, Field LD, Savoie FH 3rd. Return to highlevel throwing after combination infraspinatus repair, SLAP repair, and release of glenohumeral internal rotation deficit. Am J Sports Med. 2012;40(11):2536-2541.

82. Steinhaus ME, Makhni EC, Lieber AC, et al. Variable reporting of functional outcomes and return to play in superior labrum anterior and posterior tear. J Shoulder Elbow Surg. 2016;25(11):1896-1905.

83. Brockmeier SF, Voos JE, Williams RJ 3rd, Altchek DW, Cordasco FA, Allen AA. Outcomes after arthroscopic repair of type-II SLAP lesions. J Bone Joint Surg Am. 2009;91(7):1595-1603.

84. Provencher MT, McCormick F, Dewing C, McIntire S, Solomon D. A prospective analysis of 179 type 2 superior labrum anterior and posterior repairs: outcomes and factors associated with success and failure. $\mathrm{Am}$ J Sports Med. 2013;41(4):880-886.

85. Fedoriw WW, Ramkumar P, McCulloch PC, Lintner DM. Return to play after treatment of superior labral tears in professional baseball players Am J Sports Med. 2014;42(5):1155-1160.

86. Sayde WM, Cohen SB, Ciccotti MG, Dodson CC. Return to play after type II superior labral anterior-posterior lesion repairs in athletes: a systematic review. Clin Orthop Relat Res. 2012;470(6):1595-1600.

87. Brockmeyer M, Tompkins M, Kohn DM, Lorbach O. SLAP lesions: a treatment algorithm. Knee Surg Sports Traumatol Arthrosc. 2016;24(2): $447-455$.

88. Kibler WB, Sciascia A. Current practice for the surgical treatment of SLAP lesions: a systematic review. Arthroscopy. 2016;32(4):669-683.

89. Boileau P, Parratte S, Chuinard C, Roussanne Y, Shia D, Bicknell R. Arthroscopic treatment of isolated type II SLAP lesions: biceps tenodesis as an alternative to reinsertion. Am J Sports Med. 2009;37(5):929-936.

90. Mazoue CG, Andrews JR. Repair of full-thickness rotator cuff tears in professional baseball players. Am J Sports Med. 2006;34(2):182-189.

91. Reynolds SB, Dugas JR, Cain EL, McMichael CS, Andrews JR. Debridement of small partial-thickness rotator cuff tears in elite overhead throwers. Clin Orthop Relat Res. 2008;466(3):614-621.

92. Payne LZ, Altchek DW, Craig EV, Warren RF. Arthroscopic treatment of partial rotator cuff tears in young athletes: a preliminary report. $\mathrm{Am}$ J Sports Med. 1997;25(3):299-305.

93. Dines JS, Jones K, Maher P, Altchek D. Arthroscopic management of full-thickness rotator cuff tears in major league baseball pitchers: the lateralized footprint repair technique. Am J Orthop (Belle Mead NJ). 2016;45(3):128-133.

94. Tibone JE, Elrod B, Jobe FW, et al. Surgical treatment of tears of the rotator cuff in athletes. J Bone Joint Surg Am. 1986;68(6):887-891.

95. Codding J, Dahm DL, McCarty LP 3rd, May JH, Tucker LH, Buss DD. Arthroscopic posterior-inferior capsular release in the treatment of overhead athletes. Am J Orthop (Belle Mead NJ). 2015;44(5):223-227.

96. Yoneda M, Nakagawa S, Mizuno N, et al. Arthroscopic capsular release for painful throwing shoulder with posterior capsular tightness. Arthroscopy. 2006;22(7):801.e1-e5.

97. Nakamizo H, Nakamura Y, Nobuhara K, Yamamoto T. Loss of glenohumeral internal rotation in little league pitchers: a biomechanical study. J Shoulder Elbow Surg. 2008;17(5):795-801.

98. Mlynarek RA, Lee S, Bedi A. Shoulder injuries in the overhead throwing athlete. Hand Clin. 2017;33(1):19-34.

99. Chalmers PN, Erickson BJ, Verma NN, D'Angelo J, Romeo AA. Incidence and return to play after biceps tenodesis in professional baseball players. Arthroscopy. Epub 2017 Nov 13. 


\section{Publish your work in this journal}

The Open Access Journal of Sports Medicine is an international, peer-reviewed, open access journal publishing original research, reports, reviews and commentaries on all areas of sports medicine. The journal is included on PubMed. The manuscript management system is completely online and includes a very quick and fair

Submit your manuscript here: http://www.dovepress.com/open-access-journal-of-sports-medicine-journal

peer-review system. Visit http://www.dovepress.com/testimonials.php to read real quotes from published authors. 